\title{
Effects of Sn and Zr on the Microstructure and Mechanical Properties of Ti-Ta-Based Shape Memory Alloys
}

\author{
Y.X. Tong, B. Guo, Y.F. Zheng, C.Y. Chung, and L.W. Ma
}

\author{
(Submitted May 16, 2010; in revised form September 29, 2010)
}

\begin{abstract}
Ti-Ta binary shape memory alloys have attracted much interest due to the absence of toxic element and the low Young's modulus. However, the effects of the third element on the microstructure and mechanical property had not been well understood. In the present study, the effect of $\mathrm{Sn}$ and $\mathrm{Zr}$ additions on the microstructure and mechanical property of Ti-35Ta (at.\%) alloys has been investigated. The results show that the microstructure of the solution treated Ti-Ta-based alloys compose of equiaxial grains. The alloys consist of $\beta$-phase and $\alpha^{\prime \prime}$ martensite phase at room temperature, except for the Ti-30Ta-5Sn alloy which consists of only $\beta$-phase. This is possibly due to the presence of $S n$ which provides a stronger $\beta$-stabilized effect on quenching compared to $\mathrm{Zr}$ addition. The lattice parameter of the $\beta$-phase increased with the increase in $\mathrm{Sn}$ and $\mathrm{Zr}$ content. The addition of $\mathrm{Sn}$ and $\mathrm{Zr}$ had caused obvious increase in the tensile strength. The corrosion resistance of Ti-Ta-based alloys was also improved by adding Sn.
\end{abstract}

Keywords mechanical property, microstructure, shape memory alloy, Ti-Ta

\section{Introduction}

Titanium alloys are widely used for dental implants and orthodontic surgery applications. Although titanium and the popular Ti-6Al-4V alloys have excellent reputation for their high strength, low density (high specific strength), high immunity to corrosion and biocompatibility, the long-term performance of these alloys has raised some concerns due to the possible release of elements aluminum and vanadium which were found associated with health problems, such as Alzheimer disease, neuropathy, and allergic reaction (Ref 1-3). Another issue concerned is the mismatch between high modulus of metallic implants and low modulus of bone causing biomechanical incompatibility known as "stress shielding" problem (Ref 4). In the past decades, $\mathrm{Nb}, \mathrm{Ta}, \mathrm{Zr}$, and $\mathrm{Sn}$ have been considered excellent $\beta$-stabilizing alloying elements for titanium alloys (Ref 5), which are also biocompatible. Therefore, $\beta$-type titanium alloys, such as Ti-35.5Nb-5Ta-7Zr (Ref 6, 7),

This article is an invited paper selected from presentations at Shape Memory and Superelastic Technologies 2010, held May 16-20, 2010, in Pacific Grove, California, and has been expanded from the original presentation.

Y.X. Tong, B. Guo, and Y.F. Zheng, Center for Biomedical Materials and Engineering, Harbin Engineering University, Harbin 150001, China; and C.Y. Chung and L.W. Ma, Department of Physics and Materials Science, City University of Hong Kong, 83 Tat Chee Avenue, Kowloon Tong, Hong Kong. Contact e-mail: appchung@ cityu.edu.hk.
Ti-29Nb-13Ta-4.6Zr (Ref 8-10), and Ti-24Nb-4Zr-7.9Sn (Ref 11, 12), have been developed as biomedical shape memory and superelastic alloys.

Among these candidates, Ti-Ta binary alloys have attracted great interest due to its good combination of high strength, low modulus, as well as potential good shape memory alloy properties (Ref 13, 14). The corrosion resistance of Ti-Ta alloys is superior to that of pure $\mathrm{Ti}$, which increases with increase in Ta content (Ref 15). The effects of ternary alloying elements on phase constitution, aging behavior, and shape memory behavior of Ti-Ta binary alloys has been investigated (Ref 16-18). The decrease in the martensitic transformation temperature due to $\mathrm{Zr}$, Hf, Sn alloying in Ti-30Ta- $X$ (at.\%) was affected by larger number of valence electrons and smaller atomic radius of the alloying elements. The addition of $\mathrm{Sn}$ to Ti-Ta was found suppressing the effect of aging on shape memory behavior due to the $\omega$-phase formation ( $\operatorname{Ref} 17$ ). The substitution of $\mathrm{Zr}$ for Ta can improve the shape memory effect of Ti-50Ta alloy (Ref 18).

However, the effect of third element on the microstructure, mechanical property, and corrosion behavior of Ti-Ta binary alloys has not been reported. The aim of the present study is to investigate the effects of $\mathrm{Sn}$ and $\mathrm{Zr}$ additions on the microstructure, mechanical property, and corrosion behavior of Ti-35Ta (at.\%) alloys.

\section{Experimental Procedures}

Ti- $(35-x) \operatorname{Ta}-x \operatorname{Sn}$ and Ti- $(35-x) \operatorname{Ta}-x \operatorname{Zr}(x=0,1,5$, all in at.\%) alloys were prepared using arc melting furnace with water-cooled copper hearth under a high purity argon atmosphere from Ti wire (99.8\%), Ta wire (99.9\%), $\mathrm{Zr}$ wire (99.9\%), and Sn sheet $(99.9 \%)$ as raw materials. Owing to the big differences in melting point (Ti: $1953 \mathrm{~K}$; Ta: $3273 \mathrm{~K}$ ) and density (Ti: $4.51 \mathrm{~g} / \mathrm{cm}^{3}$; Ta: $16.6 \mathrm{~g} / \mathrm{cm}^{3}$ ) between pure Ti and 
pure Ta, the ingots were re-melted for 10 times, and flipped over after each melting to achieve chemical homogeneity. The button-shaped ingots were hot rolled $90 \%$ into approximately 1 -mm thick plates at $1173 \mathrm{~K}$, then solution treated at $1173 \mathrm{~K}$ for $3.6 \mathrm{ks}$ and quenched into water.

The microstructure was studied by optical microscope, after the samples were ground, polished, and etched in a solution composed of $\mathrm{HF}, \mathrm{HNO}_{3}$, and water (1:1:8 in volume). Phase constitution at room temperature was determined by $\mathrm{X}$-ray diffraction (XRD), using $\mathrm{Cu} \mathrm{K} \alpha$ radiation in the typical range of $2 \theta=20^{\circ}$ to $100^{\circ}$ at an accelerating voltage of $40 \mathrm{kV}$, a current of $40 \mathrm{~mA}$, and a scanning speed of $2 \% \mathrm{~min}$.

Mechanical behavior was characterized by tensile test at a strain rate of $8.33 \times 10^{-5} / \mathrm{s}$ at room temperature. The samples used for tensile tests were rectangular shaped with a gage length of $20 \mathrm{~mm}$ and a cross section of $2 \mathrm{~mm}$ (width) $\times 1 \mathrm{~mm}$ (thickness). The fracture surface was examined by scanning electron microscope (SEM).

The samples prepared for electrochemical measurements were cut from the solution-treated samples with a dimension of $1 \times 1 \times 0.1 \mathrm{~cm}^{3}$. After mechanically polished with water-proof silicon carbide paper up to $2000 \#$ grid, all the samples were cleaned with acetone, ethanol and de-ionized water in an ultrasonic bath. These samples were dried by hot air. The sample, a platinum electrode and a saturated calomel electrode (SCE) were used as working electrode, counter electrode and reference electrode, respectively. The electrolyte used to simulate human body corrosion condition was Hank's solution prepared using de-ionized water. The chemical composition of the Hank's solution is $8 \mathrm{~g} / \mathrm{L} \mathrm{NaCl}, 0.14 \mathrm{~g} / \mathrm{L} \mathrm{CaCl} \mathrm{Ca}_{2}, 0.4$ $\mathrm{g} / \mathrm{L} \mathrm{KCl}, 0.1 \mathrm{~g} / \mathrm{L} \mathrm{MgCl}{ }_{2} \cdot 6 \mathrm{H}_{2} \mathrm{O}, 0.06 \mathrm{~g} / \mathrm{L} \mathrm{MgSO}_{4} \cdot 7 \mathrm{H}_{2} \mathrm{O}, 0.35 \mathrm{~g} / \mathrm{L}$ $\mathrm{NaHCO}_{3}, 0.06 \mathrm{~g} / \mathrm{L} \mathrm{KH}_{2} \mathrm{PO}_{4}, 0.06 \mathrm{~g} / \mathrm{L} \mathrm{Na}_{2} \mathrm{HPO}_{4} \cdot 2 \mathrm{H}_{2} \mathrm{O}, 1 \mathrm{~g} / \mathrm{L}$ glucose (Ref 19). The $\mathrm{pH}$ values of the solution were maintained at 7.4 by adding $\mathrm{HCl}$ or $\mathrm{NaOH}$. The potential dynamic polarization curves were conducted from $-0.8 \mathrm{~V}$ (vs. $\mathrm{SCE}$ ) to $2.0 \mathrm{~V}$ (vs. SCE) with a scan rate of $1 \mathrm{mV} / \mathrm{s}$ after $3.6 \mathrm{ks}$ immersion.

\section{Experimental Results}

Figure 1 shows the optical microscopic images of Ti-Tabased alloys. It is seen that the microstructure is characterized by equiaxial grain. The small dark spots in Fig. 1 are possibly dislocation etch pits, which are often observed in the metallographic of heavy deformed Ti alloy. The average grain size of Ti-35Ta is about $15 \mu \mathrm{m}$ shown in Fig. 1(a). The grain size becomes slightly larger with the additions of Sn and Zr, and the grain boundary becomes wider for Ti-Ta-Sn alloys, as shown in Fig. 1(b) and (c). This implies a higher etching rate at the grain boundaries relative to the grain matrix.

It can be found from Fig. 2(a) that Ti-35Ta alloy consists of a mixture of $\beta$-phase with a BCC structure and $\alpha^{\prime \prime}$ martensite phase with an orthorhombic structure. With increase in Sn content, the diffraction peak corresponding to $\alpha^{\prime \prime}$ martensite gradually becomes weaker, and finally disappear. The addition of $\mathrm{Zr}$ does not significantly affect the phase constitution of Ti-Ta alloys. This implies that the addition of Sn may provide a stronger $\beta$-stabilized effect on quenching compared to that of $\mathrm{Zr}$. This agrees well with the previous results on Ti-30Ta (at.\%) alloys (Ref 17). Figure 2(b) shows the dependence of lattice parameter of $\beta$-phase on the content
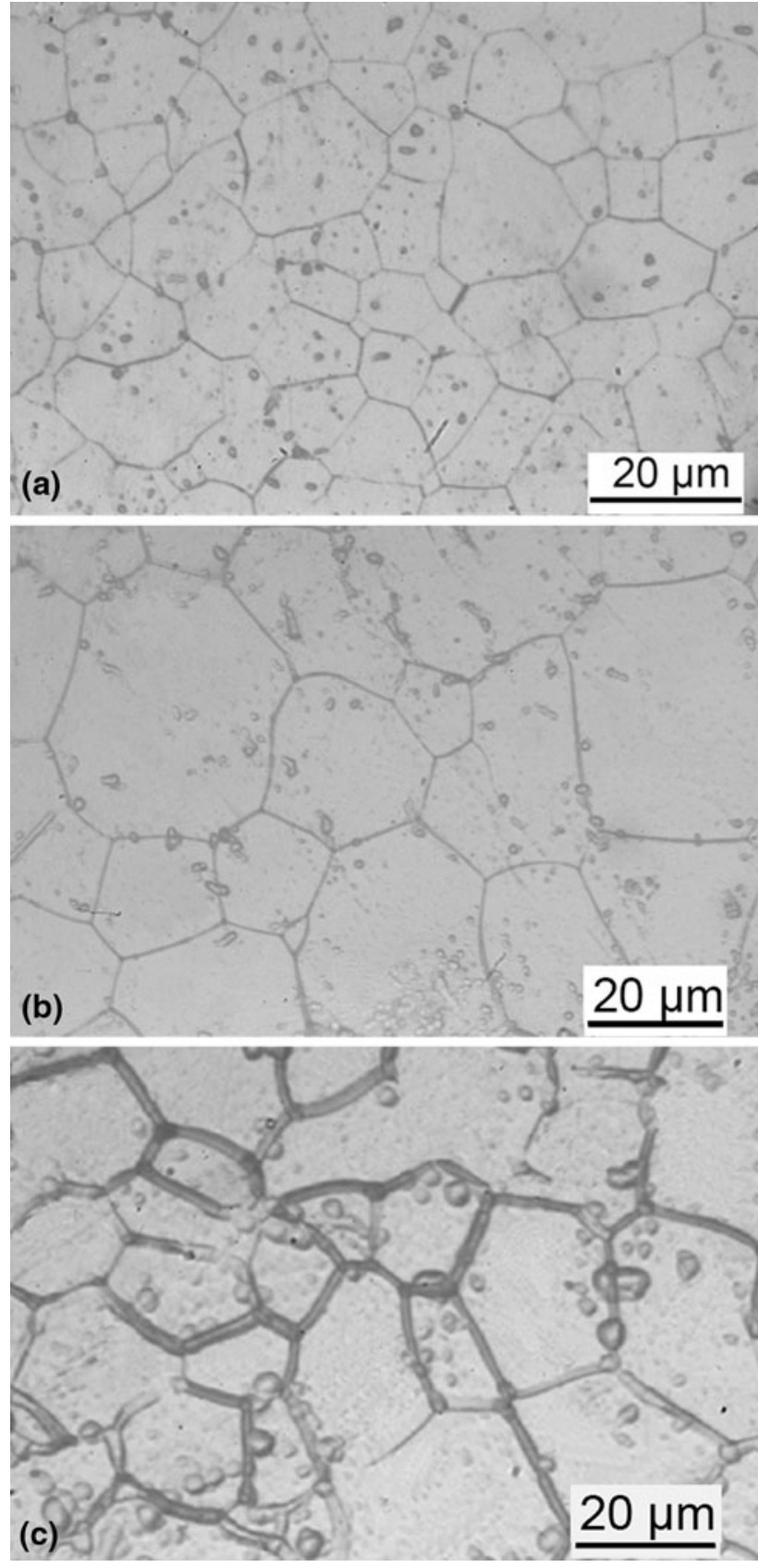

Fig. 1 Optical microstructure of Ti-35Ta (a), Ti-30Ta-5Zr (b), and Ti-30Ta-5Sn alloys (c)

of the third elements. The lattice parameter increases obviously with increase in Sn (5\%), whereas it increases only insignificantly with the addition of $\mathrm{Zr}$.

Figure 3(a) shows the stress-strain curves for Ti-Ta-based alloys. Ti-35Ta exhibits a "double yielding" phenomenon, in which the first "yielding" corresponds to rearrangement of martensite variant and the stress-induced martensite (SIM) transformation from $\beta$ to $\alpha^{\prime \prime}$, indicated by blank-headed arrows, the second "yielding" corresponds to plastic deformation of $\alpha^{\prime \prime}$ martensite labeled with black-headed arrows. The critical yield stress for SIM increases with the addition of Sn and Zr. Ti-30Ta-5Sn exhibits "single yielding" due to its lower critical stress level for plastic deformation than critical 

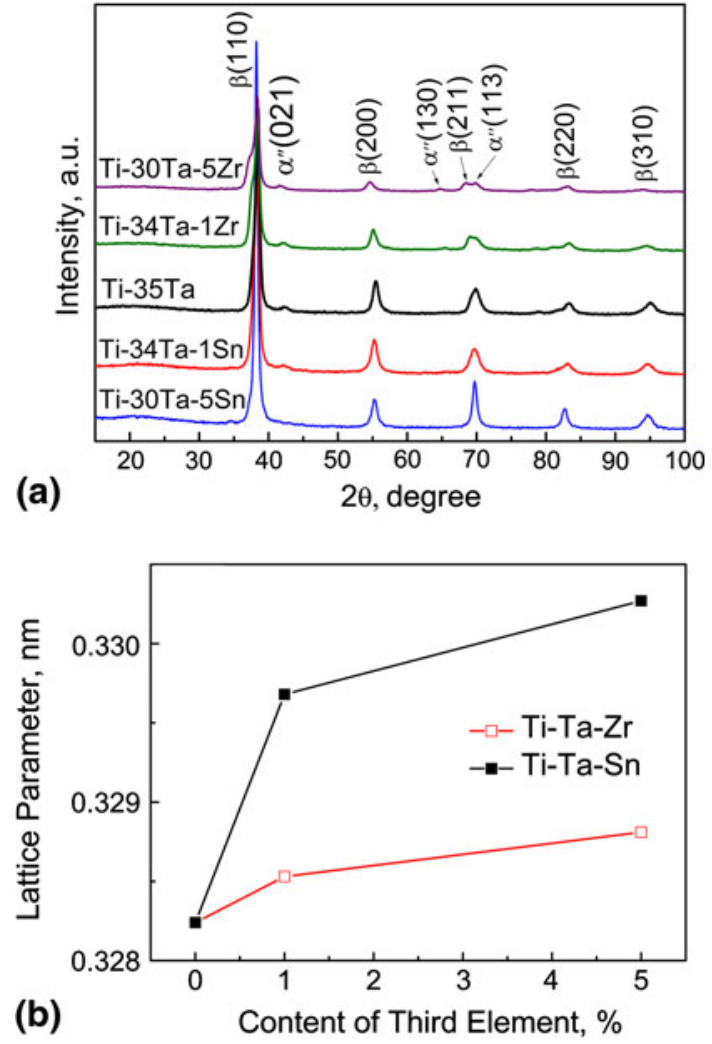

Fig. 2 XRD patterns of Ti-Ta-based alloys (a), effect of third element content on lattice parameter of $\beta$-phase in Ti-Ta-based alloys (b)

stress for SIM. This implies that parent $\beta$-phase becomes stable at room temperature and martensite transformation start temperature $(M \mathrm{~s})$ decreases with $\mathrm{Sn}$ and $\mathrm{Zr}$ content increasing. In contrast, $\mathrm{Sn}$ is more effective in stabilizing the $\beta$-phase, lowering the $M \mathrm{~s}$ and raising the critical stress for SIM compared to $\mathrm{Zr}$. These results are consistent with the XRD results shown in Fig. 2.

Mechanical properties, including tensile strength and elongation to fracture were evaluated by plotting the tensile strength against $\mathrm{Sn}$ and $\mathrm{Zr}$ content, as shown in Fig. 3(b). It can be found that the tensile strength of Ti-Ta-based alloys increases with the additions of $\mathrm{Sn}$ and $\mathrm{Zr}$. The elongation to fracture also increases with increase in Sn content monotonously. On the other hand, the elongation increases with increase in $\mathrm{Zr}$ content and reaches the maximum at $1 \%$. Subsequently, it decreases on further increase of $\mathrm{Zr}$ content to $5 \%$.

The SEM images of the fracture surface morphologies of Ti-Ta-based alloys after tensile tests are shown in Fig. 4(a-c). Ti-35Ta alloy exhibits typical ductile fracture with dimple patterns, as seen in Fig. 4(a). Although the fracture surface of Ti-30Ta-5Zr also composed of dimple patterns, a few cleavage planes can also be observed as shown in Fig. 4(b), indicating a decrease in ductility with $\mathrm{Zr}$ addition. On the contrary, the fracture morphologies of dimple patterns are more homogeneous for Ti-30Ta-5Sn alloy than that of Ti-35Ta, as shown in Fig. 4(c), which infers a better plasticity with $\mathrm{Sn}$ addition.

Figure 5 shows the potential dynamic polarization curves of Ti-Ta-based alloys after immersion in Hank's solution for
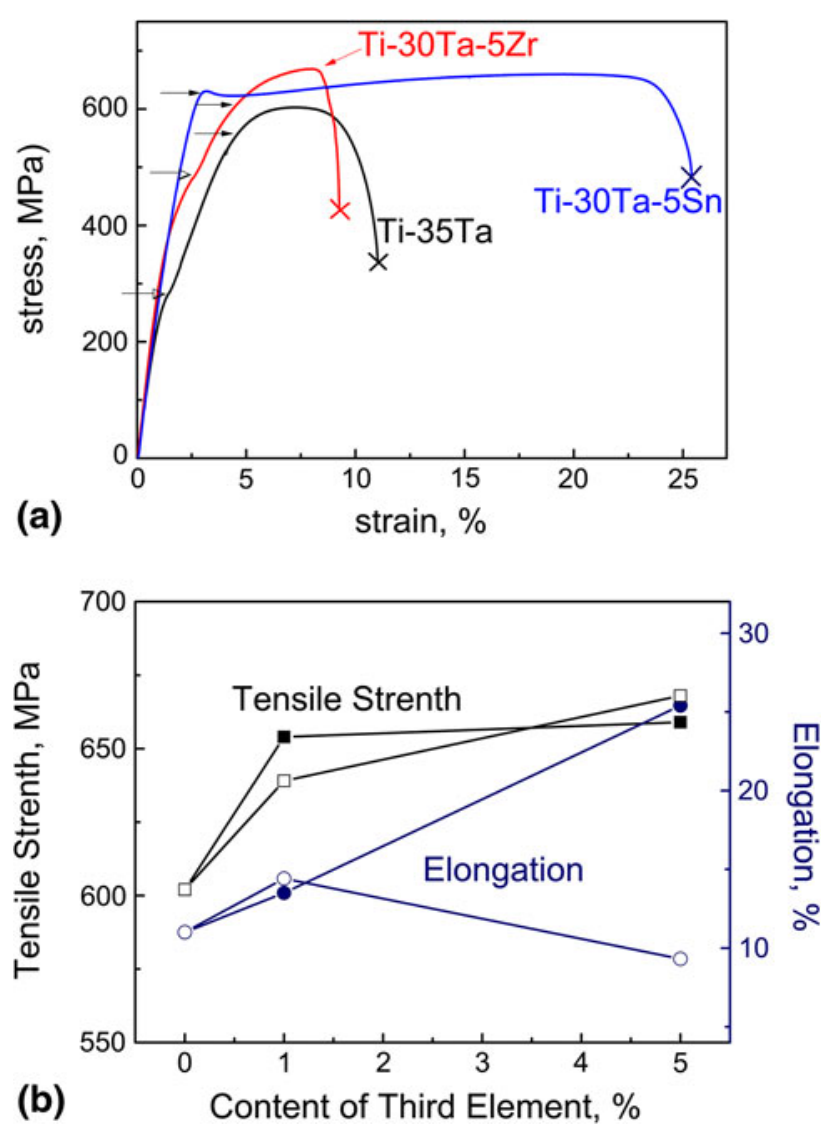

Fig. 3 Stress-strain curves of Ti-Ta-based alloys (a), effect of third element on tensile strength and elongation to fracture of Ti-Ta-based alloys (solid symbols represent Ti-Ta-Sn alloys, open symbols Ti-Ta$\mathrm{Zr}$ alloys) (b)

$3.6 \mathrm{ks}$. All of the studied alloys exhibit wide passive region, which means that the passive films formed on the surface of samples are protective, thus preventing further corrosion. It is interesting to note that Ti-35Ta and Ti-30Ta-5Sn alloys show clear active-passive transition, in contrast to $\mathrm{Ti}-30 \mathrm{Ta}-5 \mathrm{Zr}$ without showing obvious active-passive transition. The corrosion current densities $\left(I_{\text {corr }}\right)$ were estimated by Tafel analysis using both cathodic and anodic branches of the polarization curves. It is evident that Ti-30Ta-5Sn exhibits reduced $I_{\text {corr }}$, while Ti-30Ta-5Zr exhibits increased $I_{\text {corr }}$. The passivation current density $\left(I_{\text {pass }}\right)$ as determined at $0.5 \mathrm{~V}$ is approximately $10.1 \mu \mathrm{A} / \mathrm{cm}^{2}$ for Ti-35Ta, and $9.67 \mu \mathrm{A} / \mathrm{cm}^{2}$ for Ti-30Ta-5Sn. On the contrary, the $I_{\text {pass }}$ at $0.5 \mathrm{~V}$ increases to $30.4 \mu \mathrm{A} / \mathrm{cm}^{2}$ for Ti-30Ta-5Zr. The lower $I_{\text {corr }}$ and $I_{\text {pass }}$ with Sn element addition indicates an improved corrosion resistance compared to the Ti-35Ta binary alloy, while the higher $I_{\text {pass }}$ and $I_{\text {corr }}$ with $\mathrm{Zr}$ element addition indicates a poorer corrosion resistance compared to the Ti-35Ta alloy.

\section{Conclusions}

The alloys consist of $\beta$-phase and $\alpha^{\prime \prime}$ martensite phase at room temperature except for Ti-30Ta-5Sn which consists of only $\beta$-phase. The Sn element provides a stronger $\beta$-stabilized 

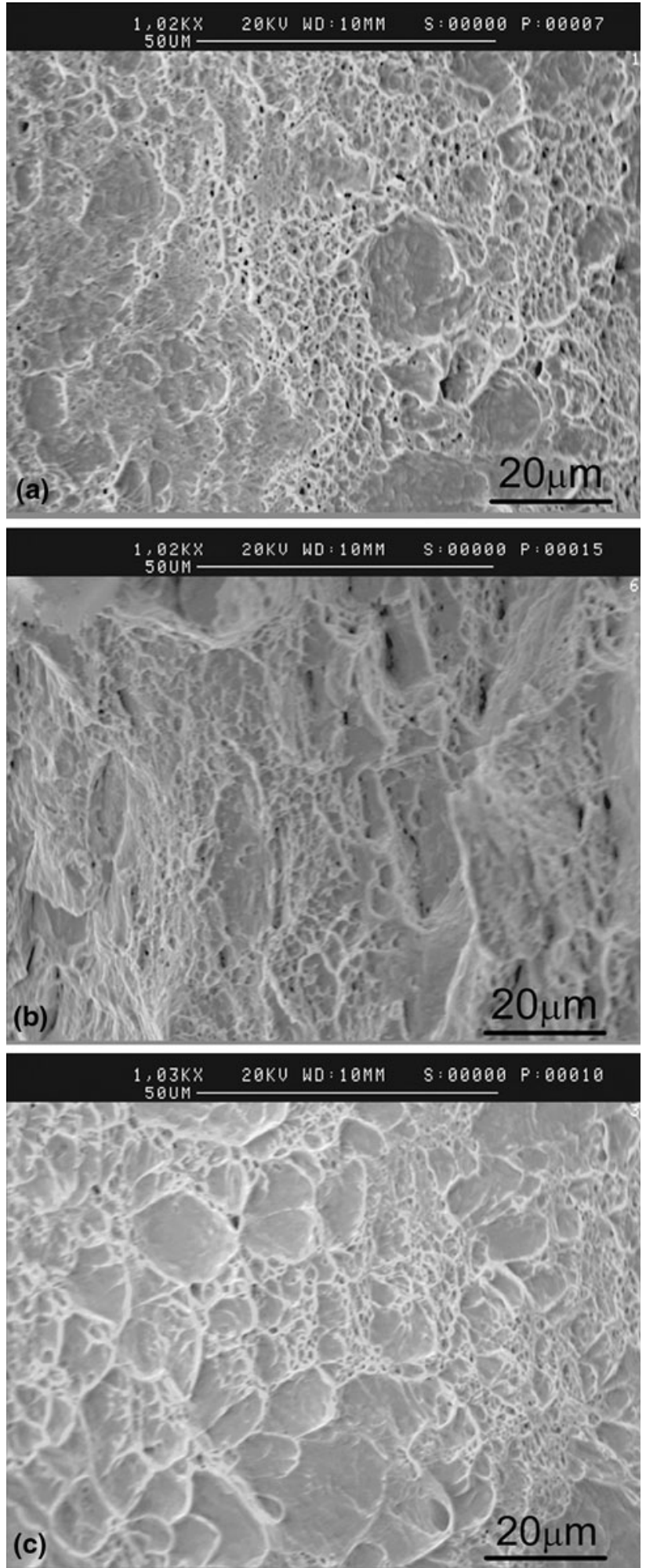

Fig. 4 SEM image of fracture surface of Ti-35Ta (a), Ti-30Ta-5Zr (b), and Ti-30Ta-5Sn alloy (c)

effect on quenching relative to $\mathrm{Zr}$ addition. The lattice parameter of $\beta$-phase increase with the increasing of Sn and $\mathrm{Zr}$ content. The tensile strength were also improved. The elongation to fracture increases with the content of $\mathrm{Sn}$ increased. The corrosion resistance is improved by $\mathrm{Sn}$ addition.

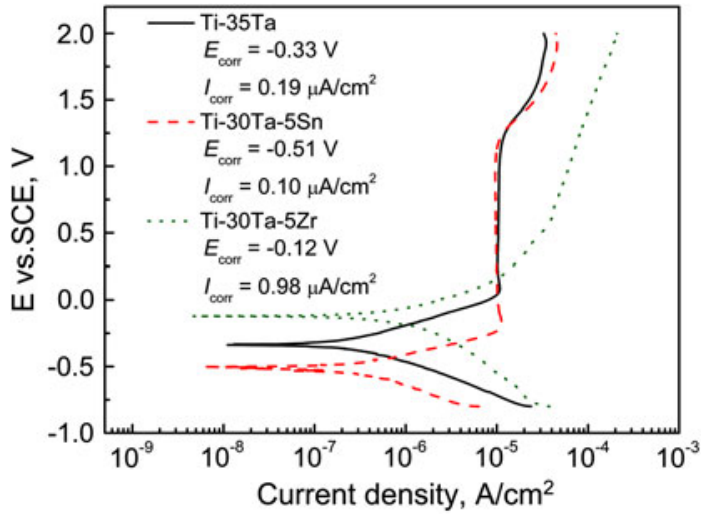

Fig. 5 The potential dynamic polarization curves of Ti-Ta-based alloys in Hank's solution

\section{Acknowledgment}

The work was supported by a grant from the Research Grant Council of the City University of Hong Kong, China (CityU SRG project \#7002215). This work was also supported by the Fundamental Research Funds for the Central Universities (HEUCF101013).

\section{References}

1. M. Geetha, A.K. Singh, R. Asokamani, R. Asokamani, and A.K. Gogia, Ti Based Biomaterials, the Ultimate Choice for Orthopaedic Implants-A Review, Prog. Mater. Sci., 2009, 54(3), p 397-425

2. B. Platt, G. Fiddler, G. Riedel, and Z. Henderson, Aluminium Toxicity in the Rat Brain: Histochemical and Immunocytochemical Evidence, Brain Res. Bull., 2001, 55(2), p 257-267

3. S. Rao, T. Ushida, T. Tateishi, Y. Okazaki, and S. Asao, Effect of Ti, $\mathrm{Al}$, and V Ions on the Relative Growth Rate of Fibroblasts (L929) and Osteoblasts (MC3T3-E1) Cells, Bio-Med. Mater. Eng., 1996, 6(2), p 79-86

4. D.R. Sumner, T.M. Turner, R. Igloria, R.M. Urban, and J.O. Galante, Functional Adaptation and Ingrowth of Bone Vary as a Function of Hip Implant Stiffness, J. Biomech., 1998, 31(10), p 909-917

5. E. Eisenbarth, D. Velten, M. Müller, R. Thull, and J. Breme, Biocompatibility of [Beta]-Stabilizing Elements of Titanium Alloys, Biomaterials, 2004, 25(26), p 5705-5713

6. M. Long, R. Crooks, and H.J. Rack, High-Cycle Fatigue Performance of Solution-Treated Metastable-[Beta] Titanium Alloys, Acta Mater., 1999, 47(2), p 661-669

7. R. Banerjee, S. Nag, and H.L. Fraser, A Novel Combinatorial Approach to the Development of Beta Titanium Alloys for Orthopaedic Implants, Mater. Sci. Eng. C, 2005, 25(3), p 282-289

8. D. Kuroda, M. Niinomi, M. Morinaga, Y. Kato, and T. Yashiro, Design and Mechanical Properties of New $\beta$ Type Titanium Alloys for Implant Materials, Mater. Sci. Eng. A, 1998, 243(1-2), p 244-249

9. M. Niinomi, D. Kuroda, K. Fukunaga, M. Morinaga, Y. Kato, T. Yashiro, and A. Suzuki, Corrosion Wear Fracture of New $\beta$ Type Biomedical Titanium Alloys, Mater. Sci. Eng. A, 1999, 263(2), p 193-199

10. M. Niinomi, Fatigue Performance and Cyto-toxicity of Low Rigidity Titanium Alloy, Ti-29Nb-13Ta-4.6Zr, Biomaterials, 2003, 24(16), p 2673-2683

11. Y.L. Hao, S.J. Li, S.Y. Sun, C.Y. Zheng, and R. Yang, Elastic Deformation Behaviour of Ti-24Nb-4Zr-7.9Sn for Biomedical Applications, Acta Biomater, 2007, 3(2), p 277-286

12. S.J. Li, T.C. Cui, Y.L. Hao, and R. Yang, Fatigue Properties of a Metastable [Beta]-Type Titanium Alloy with Reversible Phase Transformation, Acta Biomater, 2008, 4(2), p 305-317

13. Y.L. Zhou, M. Niinomi, and T. Akahori, Effects of Ta Content on Young's Modulus and Tensile Properties of Binary Ti-Ta Alloys for 
Biomedical Applications, Mater. Sci. Eng. A, 2004, 371(1-2), p 283-290

14. P.J.S. Buenconsejo, H.Y. Kim, H. Hosoda, and S. Miyazaki, Shape Memory Behavior of Ti-Ta and its Potential as a HighTemperature Shape Memory Alloy, Acta Mater., 2009, 57(4), p 1068-1077

15. K.A. de Souza and A. Robin, Preparation and Characterization of Ti-Ta Alloys for Application in Corrosive Media, Mater. Lett., 2003, 57(20), p 3010-3016

16. M. Ikeda, S.Y. Komatsu, and Y. Nakamura, Effects of Sn and $\mathrm{Zr}$ Additions on Phase Constitution and Aging Behavior of Ti-50mass\%
Ta Alloys Quenched from $\beta$ Single Phase Region, Mater. Trans., 2004, 45(4), p 1106-1112

17. P.J.S. Buenconsejo, H.Y. Kim, and S. Miyazaki, Effect of Ternary Alloying Elements on the Shape Memory Behavior of Ti-Ta Alloys, Acta Mater., 2009, 57(8), p 2509-2515

18. T. Peradze, I. Stamateli, J. Cederstrom, T. Berikashvili, A. Razov, and K. Gorgadze, Shape Memory Effect in Ti-Ta-Zr Alloys, Int. J. Appl. Electromagn. Mech., 2006, 23(1-2), p 39-43

19. Y.F. Zheng, B.L. Wang, J.G. Wang, C. Li, and L.C. Zhao, Corrosion Behaviour of Ti-Nb-Sn Shape Memory Alloys in Different Simulated Body Solutions, Mater. Sci. Eng. A, 2004, 338-440, p 891-895 